\title{
$>$ A ironia no trabalho fotográfico de Carlos Pasquetti
}

\author{
$>$ Irony in the photographic work of Carlos Pasquetti
}

\section{por Cláudio Barcellos Jansen Ferreira}

Bacharel e Mestre em Artes Visuais - História, Teoria e Crítica, pelo Programa de PósGraduação em Artes Visuais (PPGAV) da Universidade Federal do Rio Grande do Sul (UFRGS). E-mail: claudio.jansen.ferreira@gmail.com. ORCID: 0000-0002-6379-267X.

\section{Resumo}

Este artigo observa o trabalho fotográfico de Carlos Pasquetti (1948) a partir de sua relação com o retrato e a ironia, a qual o percorre na extensão que vai da sua concepção à sua criação. A aproximação com o conceito do retrato se dá pela visão de Galienne e Pierre Francastel na difícil, se possível, tarefa de defini-lo. O conceito de ironia que emprego é a interpretação de Kierkegaard. Elementos não esgotáveis pela abrangência deste artigo, retrato e ironia foram e são empreendidos no trabalho de Pasquetti, de quem recolho excertos de entrevistas concedidas, nas quais o artista apresenta um pouco da sua relação com esses elementos, os quais participam da construção de seu trabalho. Palavras-chave: Carlos Pasquetti. Ironia. Retrato. Arte contemporânea.

\section{Abstract}

This article observes the photographic work of Carlos Pasquetti (1948) focusing on his relationship with portraiture and irony, which runs from the moment of conception to the moment of creation of his work. The approach to the concept of the portrait employed here is given by Galienne and Pierre Francastel in the difficult, if possible, task of defining it. The concept of irony employed is Kierkegaard's. Portraiture and irony, elements which are not exhausted in this article, were and are used in the work of Pasquetti, who has discussed, in interviews collected here, his relationship with these elements, which participate in the construction of his work.

Keywords: Carlos Pasquetti. Irony. Portrait. Contemporary art. 
[...] aquela ali é do meu pai quando era pintor. Quando era pintor, fotógrafo, diretor de teatro e era tri-doido. (informação verbal). ${ }^{1}$

Um momento de compreensão sobre um trabalho artístico pode envolver diversos recursos aplicados pelo observador/fruidor, permanecendo como experiência não compartilhável em nenhuma das possíveis configurações pelas quais venha a ser concebida. A ironia envolvida no processo de desvendamento de cada circunstância, artística ou não, para onde se dirige a atenção ressalta do contexto linguístico condicionante da leitura experimentada.

A imagem de uma pessoa em particular, embora possa não ser classificável pelos requisitos da história da arte consagrada no gênero do retrato, pode ser creditada também por sua vocação alusiva. Seja como desdobramento do gênero em associação a outras categorias históricas ou como uma derivação de sentido do trabalho do artista que se expõe, empregando o próprio corpo. O campo de prova da sensibilidade incontida, partilhada com quem opte por justapor carga sensível equivalente, alvo de punção e pulsão, deixando ver mais do que permite a visão, sentir mais do que permitem os sentidos, criar o real.

Este artigo observa o trabalho fotográfico de Carlos Pasquetti (1948) a partir de sua relação com o retrato e a ironia, a qual o percorre na extensão que vai da sua concepção à sua criação. Com o objetivo de estabelecer uma aproximação com o conceito de retrato, como gênero constituinte da história da arte, apresento a visão de Galienne e Pierre Francastel na difícil, se possível, tarefa de defini-lo. Não menos difícil de abordar é o conceito de ironia. E, para o exercício de procurar um caminho, algum, que leve a uma aproximação com esse instrumento retórico, estoico em sua indiferença para com as preocupações teóricas dos poucos pesquisadores que o tentaram explorar, busco a interpretação de Kierkegaard. O seguidor de Sócrates confere à ironia status de componente indivisível da subjetividade humana. Elementos não esgotáveis

${ }^{1}$ Carlos Pasquetti, Entrevista concedida ao autor, 2015. 
pela abrangência deste artigo, retrato e ironia foram e são empreendidos no trabalho de Pasquetti, de quem recolho excertos de entrevistas concedidas, nas quais o artista apresenta um pouco da sua relação com esses elementos, os quais participam da construção de seu trabalho. Um texto que se proponha a discutir um trabalho artístico deve em primeiro lugar buscar as variáveis que definirão um curso estrito para a pesquisa naqueles elementos que são intrínsecos e inalienáveis ao objeto do estudo, como o próprio artista. A arte não se dá pela simples justaposição de elementos formais, ela se dá através da sensibilidade do artista. Sua subjetividade, sua afetividade, seus desejos e frustrações. A complexidade de um trabalho não se dá apenas pela utilização de uma terminologia específica de um campo de estudo, como o da ciência, por exemplo. Eventualmente a indefinição, o uso discricionário de elementos díspares, é uma provocação à consciência do leitor, para que ele talvez venha a perceber a artificialidade, ou, como diria Perelman, a falsa universalidade de um determinado auditório:

Certos auditórios especializados costumam ser assimilados ao auditório universal, tal como o auditório do cientista dirigindo-se aos seus pares. $O$ cientista dirige-se a certos homens particularmente competentes, que admitem os dados de um sistema bem definido, constituído pela ciência em que são especialistas. Contudo, esse auditório tão limitado é geralmente considerado pelo cientista não como um auditório particular, mas como sendo realmente o auditório universal: ele supõe que todos os homens, com o mesmo treinamento, a mesma competência e a mesma informação, adotariam as mesmas conclusões. ${ }^{2}$

A dificuldade na escritura da história da arte reside nessa configuração do objeto ao qual se pretende aceder. O fenômeno artístico é constituído de objetividades e subjetividades, algumas das quais facilmente descritíveis. Nem todas.

Pasquetti nasceu na cidade de Bento Gonçalves, região marcada pela persistência de traços culturais oriundos de um processo de imigração italiana ocorrido principalmente na segunda metade do século XIX. Um desses traços marcantes da comunidade ali formada é o catolicismo. O pai do artista, Camillo

\footnotetext{
${ }^{2}$ Chaïm Perelman \& Lucie Olbrechts-Tyteca, Tratado da argumentação, 1996, p. 38.
} 
Pasquetti (1903-1968), já nascido no Brasil, além de dirigir um grupo de teatro local e praticar pintura a óleo, tornou-se um renomado fotógrafo da região, requisitado para todos os tipos de trabalho. Pasquetti acompanhava o pai quando este realizava trabalhos fotográficos, como retratos de primeira comunhão, para os quais era montado um cenário adequado à ocasião.

Eu o acompanhava e carregava uma imagem de Jesus, um lírio e outras coisas. Já era uma instalação, eu sempre percebi isso. O Jesus, o lírio de plástico, supermoderno, que não precisava trocar, e eu ajudava o comungante a fazer a pose, e Jesus estava assim [faz o gesto de bênção com a mão], para ele tomar a hóstia. ${ }^{3}$

Virtualmente tudo o que se relaciona à experimentação de qualquer situação - ambiente, realização, fato, acontecimento, instalação, objeto, imagem - está sujeito aos filtros perceptivos daquele que observa, participa, experimenta. A classificação do arranjo material necessário para a produção de uma fotografia alusiva à primeira comunhão, que devia ser vista pelo protagonista sob um ponto de vista religioso, como uma instalação artística pressupõe uma determinada visão.

Nesta perspectiva, um retrato pode ser apenas um retrato? Toda classificação é reducionista. A delimitação da categoria retrato envolve, necessariamente, o julgamento de elementos formais e simbólicos voltados ao atendimento de uma expectativa criada pelo próprio princípio classificatório. Um trabalho artístico que seja exclusivamente um retrato deve essa atribuição a um princípio ordenador que usualmente visa, com certa justificação, um objetivo didático; com o fim, por exemplo, de ensinar a história da arte. Esse objetivo não se aplica a este artigo. E tanto a obrigatoriedade do uso da classificação retrato para designar um determinado tipo de trabalho quanto a sua proibição são maneiras de cerceamento igualmente comuns. Aqui, pretendo observar o limite conceitual do retrato a partir de um ponto de vista mais permeável.

\footnotetext{
${ }^{3}$ Carlos Pasquetti, Entrevista concedida ao autor, 2013.
} 
A representação símile das feições de um indivíduo específico tem início em período muito anterior aos primeiros registros escritos sobreviventes até os dias de hoje. Mas a narrativa verbal oferece um percurso aparentemente mais assertivo sobre aquilo que descreve. Como, por exemplo, o relato de Plínio, o velho, sobre Dibutades, um oleiro de Sícion, que, em seguimento à invenção de sua filha de desenhar o contorno do perfil daquele por quem estava apaixonada, copiando-lhe a sombra projetada na parede, fez um molde de argila sobre o desenho e o queimou, criando uma efígie em relevo. ${ }^{4}$ Uma maneira igualmente econômica de representar uma pessoa de perfil ganhou na França, em meados do século XVIII, o nome de Silhouette, em referência a um Controlador Geral de Finanças o qual impunha de fato um grande controle financeiro ao país. ${ }^{5} \mathrm{O}$ processo de recortar perfis em um papel preto brilhante era rápido e barato, mas apenas o seu sucessor, o Physionotrace, criado por Gilles-Louis Chrétien (17541811), aperfeiçoa a transferência do perfil do modelo e se torna popular entre 1786 e 1830, baseando-se no princípio do pantógrafo. ${ }^{6}$ Mas as maneiras de representar aspectos fisionômicos, embora aludam de forma icônica a alguém em particular, são abstrações bidimensionais às quais é creditado o poder da identificação.

As maneiras de representar à semelhança a figura de uma pessoa, empreendidas também desde a antiguidade, normalmente envolvendo um grande e virtuoso trabalho manual, culminam na baixa Idade Média e no Renascimento, com o crescente aperfeiçoamento técnico, especialmente o uso da tinta a óleo. Elas eram valorizadas por apresentarem os retratados não apenas em suas características físicas, mas também por buscarem transparecer o caráter do modelo. No século XVIII na França, segundo Francastel, o retrato só terá uma renovação após o retorno de Jean-Honoré Fragonard (1732-1806) de sua viagem à Itália. Seus retratos realizados entre 1767 e 1774, para o autor, abriram caminho para o retrato romântico. ${ }^{7}$ No mesmo período em que Fragonard esteve na Itália,

\footnotetext{
${ }^{4}$ Philippe Dubois, O ato fotográfico e outros ensaios, 2012, p. 117 a 118.

${ }^{5}$ Gisèle Freund, Photographie et société, 2000, p. 14.

${ }^{6}$ Ibidem, p. 15.

${ }^{7}$ Galienne Francastel \& Pierre Francastel, El retrato, 1978, p. 185 a 188.
} 
curiosamente lá trabalhava um retratista com o mesmo sobrenome de Carlos Pasquetti, o veneziano Fortunato Pasquetti (1690-1773). Atuante no século XVIII e reconhecido por retratos de personagens ilustres, é apresentado pelo historiador da arte James Hobbes, em The picture collector's manual (1849), como tendo se tornado "[...] famoso pela sua excelente similitude nos retratos." ${ }^{\text {" }}$

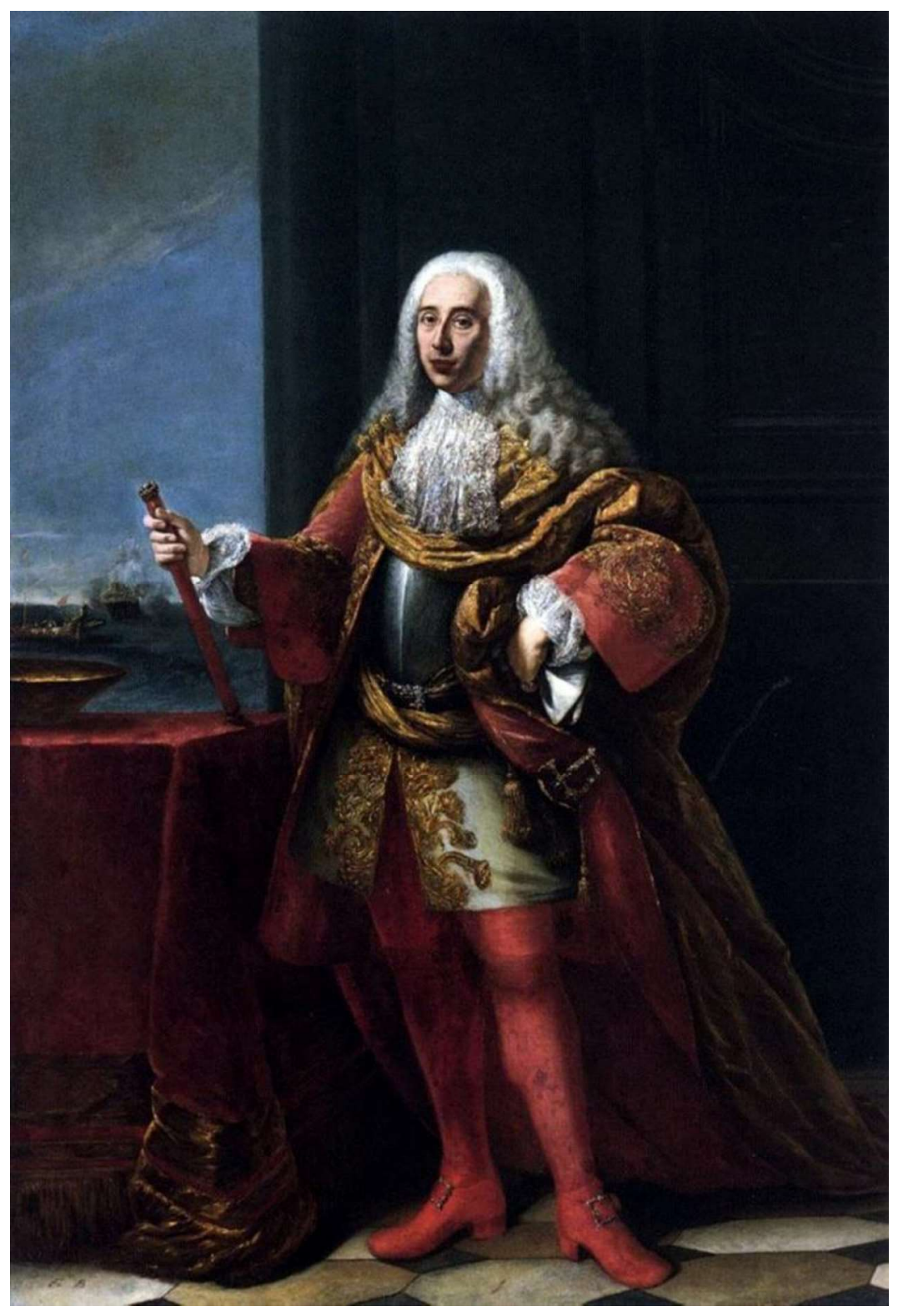

Figura 1

Fortunato Pasquetti, Retrato do Provveditore Generale da Mar Girolamo Maria Balbi, 1751 - 1753.

8 James R. Hobbes, The picture collector's manual, 1849, p. 325. 
Entretanto, mesmo as mais virtuosas representações permanecem confinadas a limites próximos àqueles aos quais uma simples silhueta está submetida. A definição de retrato sucumbe à análise de uma suposta consistência fatual eventualmente atribuída à sua classificação, como sugere Didi-Huberman:

A definição corrente do retrato como representação semelhante de uma pessoa existente - essa definição não nos vale de nada, simplesmente na medida em que as práticas concretas geralmente designadas sob o termo de 'retratos' tecem cada uma incríveis tranças contraditórias de representações e de presenças, de semelhanças e dessemelhanças, de seres e de existências, sem contar o tirânico pequeno labirinto que a palavra 'pessoa', por si só, forma. ${ }^{9}$

A inextricável condição linguística da definição verbal, pretensiosa de abarcar um conceito volátil, estruturado sobre uma classificação muito mais retórica do que concretamente existente, termina por se tornar uma indefinição. A ligação entre a representação e o modelo, a pessoa referida, se dá a partir de elementos formais os quais provocam a lembrança da pessoa conhecida. Uma classificação que se propusesse estrita demandaria do retrato a presença de elementos de identificação do retratado, apenas. Mesmo a ideia de imagem fiel do modelo incorre em converter o sujeito retratado apenas em aparência, deixando logo de ser ele mesmo, já que ninguém é apenas a representação de si. Francastel, por sua vez, coloca o problema do estudo do retrato na perspectiva do problema da interpretação:

\begin{abstract}
Si uno retiene la definición que considera el retrato como la imagen fiel del modelo, es evidente que habrá que eliminar todas las representaciones humanas a las que se ha atribuido un sentido extrapersonal, es decir, a su gran mayoría. Si retenemos en cambio la fórmula 'algunos aspectos', nuestro campo de investigación será entonces mucho más amplio. Y si finalmente agregamos el de la interpretación subjetiva, en este caso el campo se hará ilimitado, es decir, inexplorado. ${ }^{10}$
\end{abstract}

Os autores ainda propõem delimitar o vasto campo da interpretação subjetiva levando em consideração as obras para as quais houve a intenção do artista pelo retrato e, em alguma medida, o consentimento do modelo. De alguns elementos formais de um perfil projetado na parede a um conjunto de atributos

\footnotetext{
${ }^{9}$ Georges Didi-Huberman, O rosto e a terra, 1998, p. 62.

${ }^{10}$ Galienne Francastel \& Pierre Francastel, Op. Cit., p. 15.
} 
e delimitações convencionais, e novamente para alguns poucos aspectos formais, talvez indiciais, na verdade icônicos, o retrato pode ser inclusive a designação de um item pessoal, pertencente ao retratado, tornado ícone de sua presença, virtual. O retrato também pode ser uma representação virtuosa do modelo realizada de maneira não virtuosa, e sim mecânica.

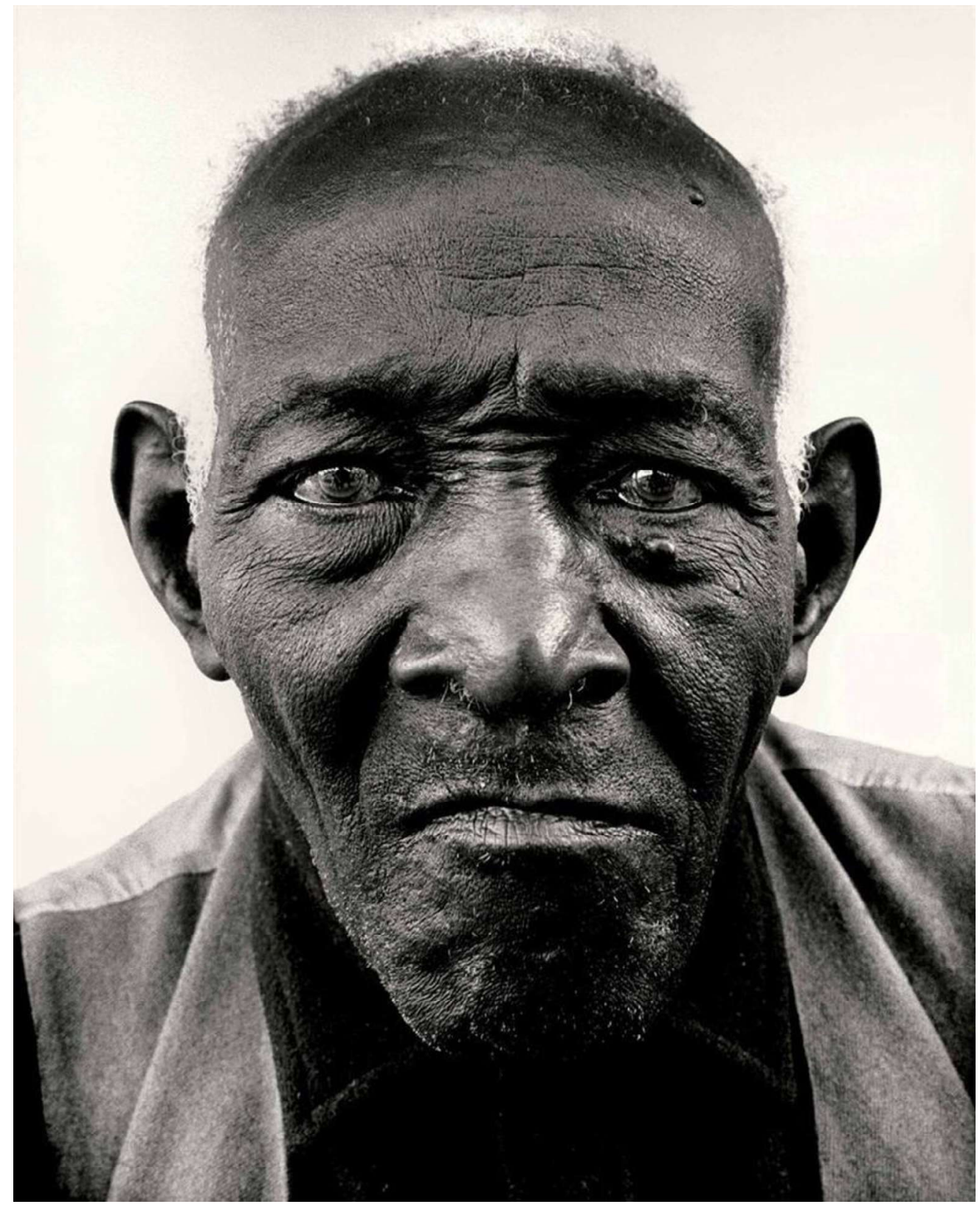

Figura 2

Richard Avedon, William Casby, nascido na escravidão, Algiers, Louisiana, 1963. 
Barthes, em seu livro A câmara clara (1980), parte de um pressuposto subjetivo para realizar sua análise. Ele vê na fotografia um meio transparente através do qual se projeta a imagem de um modelo que em algum momento no passado esteve ali, isso foi. A crença na veracidade da imagem técnica é um mito presente, assim como Plínio conta que "[...] dizem, [...]" em uma competição com Parrásio, Zêuxis teria pintado um cacho de uvas "[...] com tanto naturalismo que os pássaros voaram para o local onde a pintura foi exibida." ${ }^{.11}$ Além de Zêuxis ter admitido sua derrota, por ter sido ele próprio enganado pelo naturalismo da cortina pintada por Parrásio, hoje é conhecido que "aves e alguns outros vertebrados (incluindo camundongos) têm sensibilidade visual ao ultravioleta."12 O que tornaria o fato de os pássaros terem se enganado com a pintura uma prova da distorção na cor da mesma, relativamente à visão humana. A cor que, limitada ao preto e branco da quase totalidade das imagens citadas no livro de Barthes, indica que a transparência da fotografia de fato é um filtro, uma chave de leitura convencional entre o fotógrafo e a assistência, a qual decide ver ali o que foi.

Ver além da fotografia é um sintoma comum de manifestação da cultura. Ver a fotografia como um meio transparente é dizer que o importante ali é o conteúdo projetado sinedoquicamente pela imagem, já que a imagem é uma máscara feita a partir de uma visada do que, em princípio, existiu. Nesse sentido, pode ser considerada a contingência da fotografia, prisioneira dos sentidos que lhe são associados, inexoravelmente.

Já que toda foto é contingente (e por isso mesmo fora de sentido), a Fotografia só pode significar (visar uma generalidade) assumindo uma máscara. É exatamente essa palavra que Calvino emprega para designar aquilo que faz de uma face o produto de uma sociedade e de sua história. ${ }^{13}$

O retrato de William Casby fala de Avedon, do trabalho em estúdio, do fundo neutro, da profundidade de campo que apresenta todos os detalhes do rosto do modelo, da distância focal que coloca o observador mais próximo do que

\footnotetext{
${ }^{11}$ Pliny, the elder, The Natural History of Pliny, 1857, p. 251.

${ }^{12}$ Richard W. Hill, Gordon A. Wyse \& Margaret Anderson, Fisiologia Animal, 2012, p. 369.

${ }^{13}$ Roland Barthes, A Câmara Clara, 1984, p. 58.
} 
o afastamento convencional ao convívio social permite. E, depois de ler o título do trabalho, põe-se a projetar uma suposta realidade do personagem, plausibilíssima, a qual jamais ofereceria qualquer dúvida sobre a sua seriedade. Então, torna-se possível perguntar: será que Casby sabia sorrir?

As escolhas do fotógrafo definem o resultado da imagem, tanto mais quanto maior for a sua habilidade em lidar com os instrumentos que definem seu trabalho. A luz, a máquina, a lente, a sensibilidade, a distância, sim, mas também o tipo de comunicação que se estabelece entre o retratista e o retratado, o que se fala, o que se indica, o que se sugere, de parte a parte. A convergência da comunicação entre artista e modelo, e das decisões tomadas por um e por outro, em conjunto ou individualmente, resulta no retrato idealizado pelo personagem de Calvino, a máscara.

Ele tinha que seguir o caminho oposto: apontar para um retrato completamente na superfície, evidente, inequívoco, que não eludisse a aparência convencional, o estereótipo, a máscara. A máscara, sendo antes de tudo um produto social, histórico, contém mais verdade do que qualquer imagem que afirma ser 'verdadeira'; ela carrega uma quantidade de significados que serão gradualmente revelados. ${ }^{14}$

Ele rejeita o instantâneo em favor da imagem construída, carregada de atribuições conferidas pelas escolhas assumidas pelas duas manifestações individuais as quais, associadas, produzem a máscara, projeção de significados sociais e históricos. A leitura dessa imagem deve ser capaz de revelar as camadas de significados ali reunidos, mas também de provocar a evocação de significados outros, projetados a partir da experiência social e histórica do outro que a vê. $\mathrm{Na}$ proposta de Barthes contra a redução da fotografia a um eventual princípio científico, uma Mathesis universalis, ele leva em consideração apenas as fotografias que existiam para ele, ou seja, nas quais reconhecia um valor subjetivo. E indica que existe a possibilidade de buscar um desvelamento da

\footnotetext{
${ }^{14}$ Italo Calvino, The adventure of a photographer, 2010, p. 47, tradução minha: "He had to follow the opposite path: aim at a portrait completely on the surface, evident, unequivocal, that did not elude conventional appearance, the stereotype, the mask. The mask, being first of all a social, historical product, contains more truth than any image claiming to be 'true'; it bears a quantity of meanings that will gradually be revealed."
} 
fotografia a partir de uma ligação pessoal com aquelas fotografias que significam para quem as estuda, consideradas em sua singularidade. Calvino escreve, pouco tempo após o acidente que vitimou Barthes, Em memória de Roland Barthes, sobre a contribuição do autor para a abordagem da fotografia.

Essa ciência da unicidade de cada objeto que Roland Barthes continuamente margeou com os instrumentos da generalização científica e ao mesmo tempo com a sensibilidade poética aplicada na definição do singular e do irrepetível (essa gnosiologia estética ou eudemonismo do entender) é a grande coisa que ele - não digo nos ensinou, porque não se pode ensinar nem aprender - nos demonstrou que é possível: ou pelo menos que é possível buscá-la. ${ }^{15}$

A aproximação do conhecimento à estética possui, como é característico de asserções teóricas fundamentais, uma simplicidade evidente. Não obstante nesse caso, contrariamente a muitos outros, a aplicação envolve o reconhecimento de uma limitação incontornável, o próprio sentimento em relação ao objeto de estudo. Não se trata apenas da escolha das imagens sobre as quais dedicar seu esforço de análise, mas principalmente, diante das imagens escolhidas, permitir o surgimento do motivo do significado que provocou a própria escolha.

Pesquisando junto à Secretaria de Cultura de Bento Gonçalves, pude dispor de uma boa amostra de fotografias feitas no âmbito municipal. Dentre elas foi possível identificar um grupo de imagens realizadas pelo pai de Pasquetti. Imagens aéreas, trabalhos da prefeitura, eventos da comunidade local, alguns retratos. Um retrato em particular chamou minha atenção, uma tomada em estúdio, composta por uma cortina pesada sobre um fundo em pintura mural de céu com nuvens, piso de ladrilhos hidráulicos e um plinto de mármore, sobre o qual repousa um vaso metálico com um arranjo de flores brancas.

\footnotetext{
${ }^{15}$ Italo Calvino, Em memória de Roland Barthes, 2010, p. 85 a 86.
} 


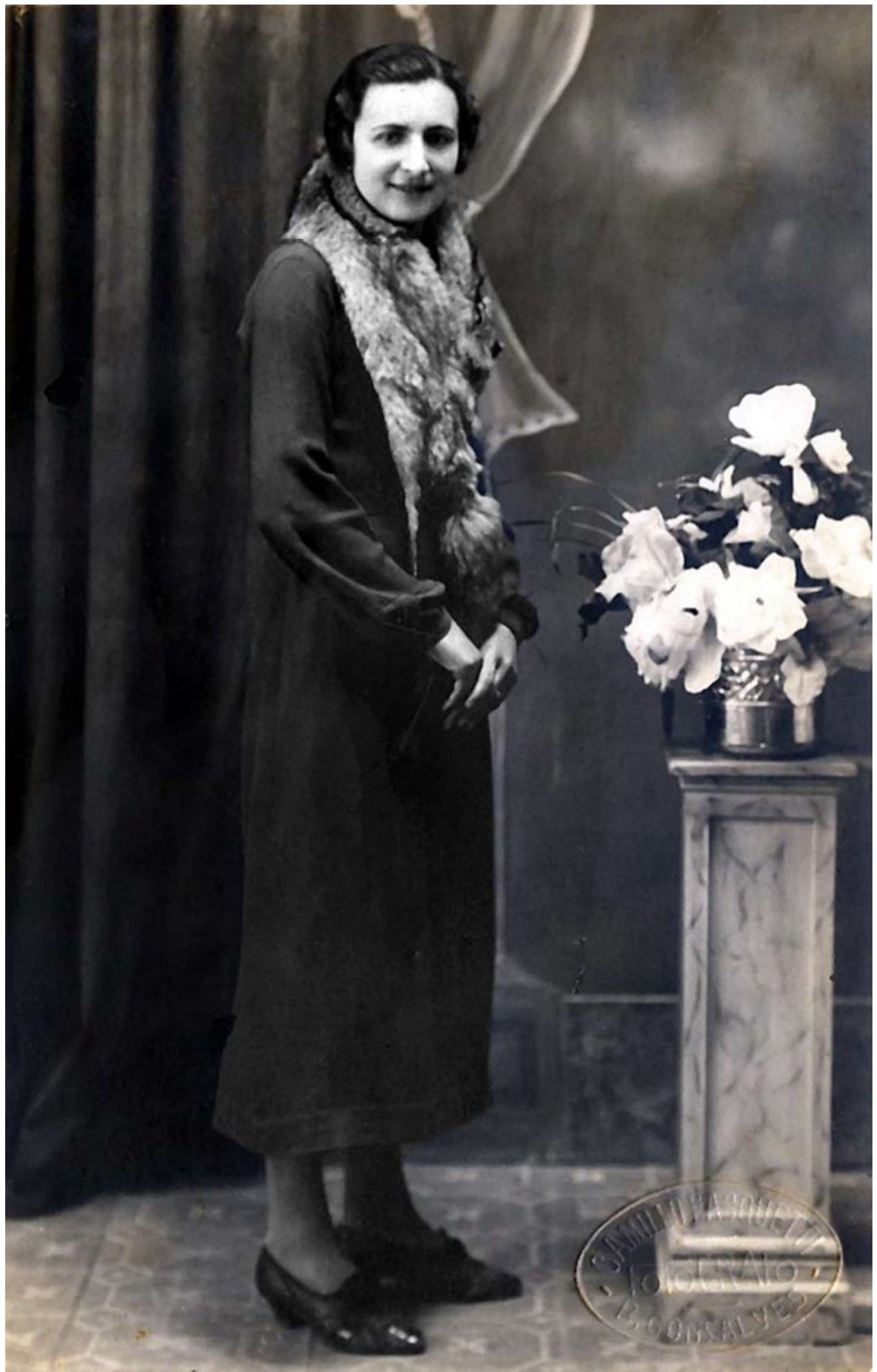

Figura 3

Camillo Pasquetti, Retrato de Gentile Ozelame, 1939. 
A retratada, uma certa Sra. Gentile, de vestido, sapato e bolsa escuros, fechados e sem enfeites, que entretanto usa uma pele no pescoço. Ela era uma mulher magra e de compleição alongada, o que gera um certo contraste com seu rosto redondo e muito claro. Uma pose convencional, com o corpo a três quartos e com o rosto quase de frente para a câmera. Na parte superior do tronco, devido à grande indiferenciação do vestido longo escuro, que parece repetir a cortina ao fundo, o contraste não é tão visível quanto nos pés, com um sapato de bico fino. O perfil esguio e a pele muito clara contrastam os sapatos, que enfatizam os pés não muito pequenos, o que sugere uma certa abordagem jocosa em relação à figura feminina. Entretanto, provavelmente essa decisão foi tomada pelo fotógrafo para ressaltar uma Sra. Gentile integrante da comunidade de imigração italiana, portadora de um biótipo que a aproximava daquela mesma origem comum. Mas também apresenta uma pessoa bem estabelecida, com sapatos finos e a pele ao redor do pescoço, produtos de manufatura especializada.

Conforme já foi mencionado, o autor da foto, Camillo Pasquetti, desempenhava artes como a pintura, o teatro e a fotografia, obtendo, especialmente nesta última, um grande reconhecimento local. A atitude expansiva e a atuação em diversas áreas exigiam disposição e comunicação. Quando seu filho Carlos Pasquetti diz que o pai era tri doido, ele se refere à capacidade de articular essas atividades díspares, embora todas ligadas à arte. E a ironia, característica presente não apenas em seu trabalho, mas também em sua própria maneira de se relacionar profissional e pessoalmente, como ele diz, "vem de berço". 16

Em 1966, já na Escola de Belas Artes, como se chamava à época, da Universidade Federal do Rio Grande do Sul, a ironia passa a fazer parte de seu trabalho artístico. Ela participa de sua criação artística em diversos estágios de construção do trabalho, mas mesmo a sua face mais superficial se encontra conectada organicamente ao cerne de onde se origina a sua manifestação.

\footnotetext{
${ }^{16}$ Carlos Pasquetti, Op. Cit., 2015.
} 
Diferentemente do emprego da ironia como um recurso retórico externo à construção da obra, Pasquetti não a incorpora ao trabalho, ela está lá desde o princípio, desde sua concepção. E sua função é lógica e ilógica concomitantemente. Lógica pelo caráter retórico que inalienavelmente a acompanha, ilógica por motivo aproximadamente inverso. Ao rejeitar a afirmação direta, ou a significação direta, ela propõe uma aporia, uma interrupção no discurso, uma provocação ao interlocutor, ao observador, àquele que recebe a missão de desvendar, por si, significados que só dizem respeito a ele mesmo.

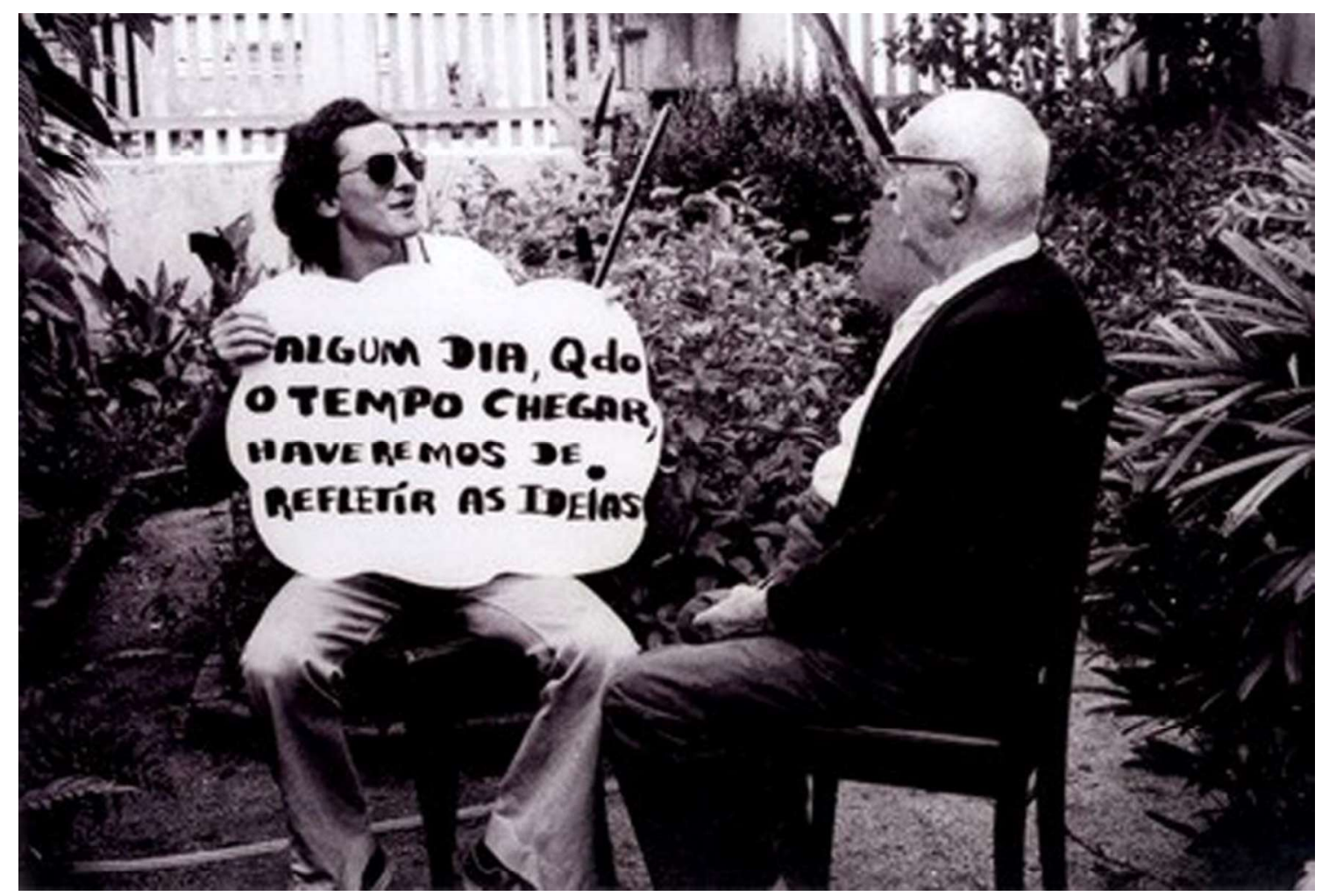

Figura 4

Carlos Pasquetti, Max, 1968.

Em 1968, com Max, Pasquetti propõe claramente uma questão intelectual. As ideias de Max talvez sejam sobre os conflitos que marcaram esse ano pelo mundo. Guerras, violências, arbitrariedades, injustiças. Uma leitura histórica. No 
entanto, pode não ser exatamente assim. Um personagem emite uma mensagem e olha para um suposto interlocutor, um senhor bastante idoso. Se a mensagem fosse para esse outro personagem, haveria um problema com a comunicação: se para o primeiro a expressão Algum dia, quando o tempo chegar projeta um futuro incerto, para o outro certamente o tempo parece já ter chegado. Então, talvez a mensagem seja para o observador da imagem. Mas por que só iremos "refletir as ideias" nesse tal futuro indeterminado? E a atitude desse personagem jovem, de óculos escuros, não parece estar levando muito a sério o próprio discurso. Irônico?

Bem, tomando-se a imagem fotográfica pela metáfora comum do espelho da realidade, seria possível entender o refletir como um repetir, um reproduzir. Mas quais ideias seriam então reproduzidas ou repetidas, as do personagem idoso? Talvez nem toda ironia seja alegre. E talvez o conteúdo da mensagem não seja realmente intelectual. Quem sabe os óculos escuros não sejam irreverência, mas sim o oposto. $O$ meio de ver o que não está mais lá. E talvez as ideias que o jovem prevê que um dia refletirá sejam o legado de alguém que desapareceu. Talvez Pasquetti proponha, com um fio de sutil ironia, o que já seria um reflexo, uma questão emocional. Nesse ano casualmente faleceu o pai do artista.

Jankélévitch, na primeira página de seu livro L'ironie (2011), transforma a ironia em uma personagem que vai procurar o perigo onde ele se encontra trancafiado e o desafia, brinca com ele, busca uma espécie de diversão perigosa que não se furta a superar o perigo de morrer a todo o instante.

A manobra, de fato, pode dar errado, e Sócrates está morto; porque a consciência moderna não tenta impunemente as criaturas monstruosas que aterrorizaram a velha consciência. No entanto, o espírito da ironia é o espírito do relaxamento, e ele aproveita a menor trégua para reiniciar o jogo. ${ }^{17}$

Sócrates (c. 469 a.C. - 399 a.C.) está morto, mas, apesar de seu desaparecimento precoce ter sido causado pela não superação do impasse entre a

\footnotetext{
${ }^{17}$ Vladimir Jankélévitch, L'ironie, 2011, p. 9-10, tradução minha: "Le manège, à vrai dire, peut mal tourner, et Socrate en est mort; car la conscience moderne ne tente pas impunément le créatures monstrueuses qui terrorisèrent la vieille conscience. Pourtant l'esprit d'ironie est bien l'esprit de détente, et il profit de la moindre acalmie pour reprendre ses jeux."
} 
incompreensão frente ao seu argumento por aqueles que o julgavam e sua intransigência na manutenção do mesmo, seu pensamento sobreviveu. Verdadeiramente o pensamento de Sócrates se constitui em um marco referencial na história da filosofia ocidental, sendo a ferramenta que empregou para a construção desse pensamento a ironia. O que diferencia a ironia do riso é a possibilidade de articulação de um pensamento complexo que, embora não seja direto e objetivo, ou por virtude disso, é capaz de mudar a compreensão humana.

Kierkegaard buscou traduzir a visão originalmente concebida por Sócrates, que, ironicamente, enfrentou a morte, presente da realidade, em defesa da mais profunda verdade interior. A partir do exemplo de Sócrates, Kierkegaard apresentou à humanidade um espelho, em cuja profundidade cada indivíduo pode encontrar a sua própria e inalienável verdade subjetiva. A frase final compilada por Platão na Defesa de Sócrates contém, pela última vez, a ironia socrática: "E agora está realmente na hora de partir, eu para ser executado e vocês para continuarem vivendo. Mas qual de nós vai para uma vida melhor não é claro para todos, exceto para Deus."18 A profundidade sensível das palavras de Sócrates não diminui a sutileza de seu pensamento, por outro lado, a frase reúne mais uma vez a pergunta que ele propõe como defesa. O paradoxo da divindade, fonte de todo o conhecimento e, por isso, sabedora do destino de todos os indivíduos, é empregado como a aporia que é, sustentado pela acusação de não reconhecer os deuses da cidade. A resposta à questão de quem vai ter uma vida melhor não apenas premia quem viveu em retidão como provoca em cada indivíduo um questionamento que, ironicamente, não vai deixar Sócrates morrer. Em Max, quando Pasquetti projeta refletir as ideias no futuro, é possível fazer um paralelo com a posição de Kierkegaard, por sua vez refletindo as ideias de Sócrates. A ironia no trabalho de Pasquetti conduz igualmente a uma aporia, um questionamento a ser respondido pela percepção do observador, que se

\footnotetext{
${ }^{18}$ Plato, Socrates Of Athens, 2007, p. 35, tradução minha: "And now it really is time to depart, I to be executed and you to continue living. But which of us goes to a better life is unclear to everyone except to the god."
} 
renova de acordo com o conjunto de expectativas investidas por este na interpretação pessoal do trabalho.

Kierkegaard também critica a visão de Hegel por nunca haver ele associado a ironia socrática a uma possibilidade de abordagem de matérias sérias. Hegel diz: "Nos últimos tempos muito se tem dito sobre a ironia socrática que, como toda dialética, dá força ao que é tomado imediatamente, mas apenas de forma a permitir à dissolução inerente a ela vir a ocorrer; e nós podemos chamar isso de ironia universal do mundo."19 Se Hegel pensa que a ironia não ocupa um espaço vital no pensamento de Sócrates, Kierkegaard contrasta completamente esse pensamento, trazendo o conceito de ironia para o centro de sua pesquisa. E, inspirado por Sócrates, consagra a ironia como um instrumento de libertação da subjetividade:

Na ironia, o sujeito está negativamente livre, pois a realidade que lhe deve dar conteúdo não está aí. [...] Mas esta mesma liberdade, este flutuar, dá ao irônico um certo entusiasmo, na medida em que ele como que se embriaga na infinitude das possibilidades, na medida em que ele, quando precisa de um consolo por tudo o que naufraga, pode buscar refúgio no enorme fundo de reserva da possibilidade. ${ }^{20}$

Kierkegaard reconhece a ironia como o instrumento utilizado sabiamente por Sócrates, a fim de oferecer à subjetividade a liberdade negativa para criar a sua própria interpretação alternativa do conteúdo/objeto, uma vez que destrói a concepção da realidade restritiva do sujeito e cria infinitas possibilidades. Mas essa ação se encontra mesmo no princípio do embate da consciência individual com a realidade, melhor dizendo, a concepção individual da realidade.

A ironia, desde que participa centralmente do mecanismo de funcionamento da percepção do real, acompanha todas as oportunidades nas quais o indivíduo experimenta a condição de idealizador da realidade. Essa concepção é condizente com o postulado por Arthur Schopenhauer (1788 - 1860),

\footnotetext{
${ }^{19}$ Georg W. F. Hegel, Lectures on the history of philosophy, 1892, p. 400, tradução minha: "In recent times much has been said about the Socratic irony which, like all dialectic, gives force to what is taken immediately, but only in order to allow the dissolution inherent in it to come to pass; and we may call this the universal irony of the world".

${ }^{20}$ Søren Kierkegaard, O conceito de ironia, 2013, p. 263.
} 
que, em O mundo como vontade e representação, apresenta a tese de que "tudo o que existe, existe para o pensamento, isto é, o universo inteiro apenas é objeto em relação a um sujeito, percepção apenas, em relação a um espírito que percebe. Em uma palavra, é pura representação." ${ }^{21} \mathrm{~A}$ ironia, associada à representação que o indivíduo faz do mundo, inevitavelmente acompanha este no deslocamento em direção à arte. E quanto mais a arte se aproxima da vida em suas particularidades cotidianas, mais evidente se torna a presença da ironia e sua articulação com os processos de representação que o sujeito faz do mundo para si.

A ironia acompanha o movimento do indivíduo frente à representação que faz para si da realidade percebida. A arte acompanha de maneiras diferentes esse movimento em momentos diferentes da sua história. No trabalho fotográfico de Pasquetti, esse procedimento é realizado em cada enquadramento e em cada captura de uma visão, objeto da representação de uma realidade percebida e apropriada pelo artista.
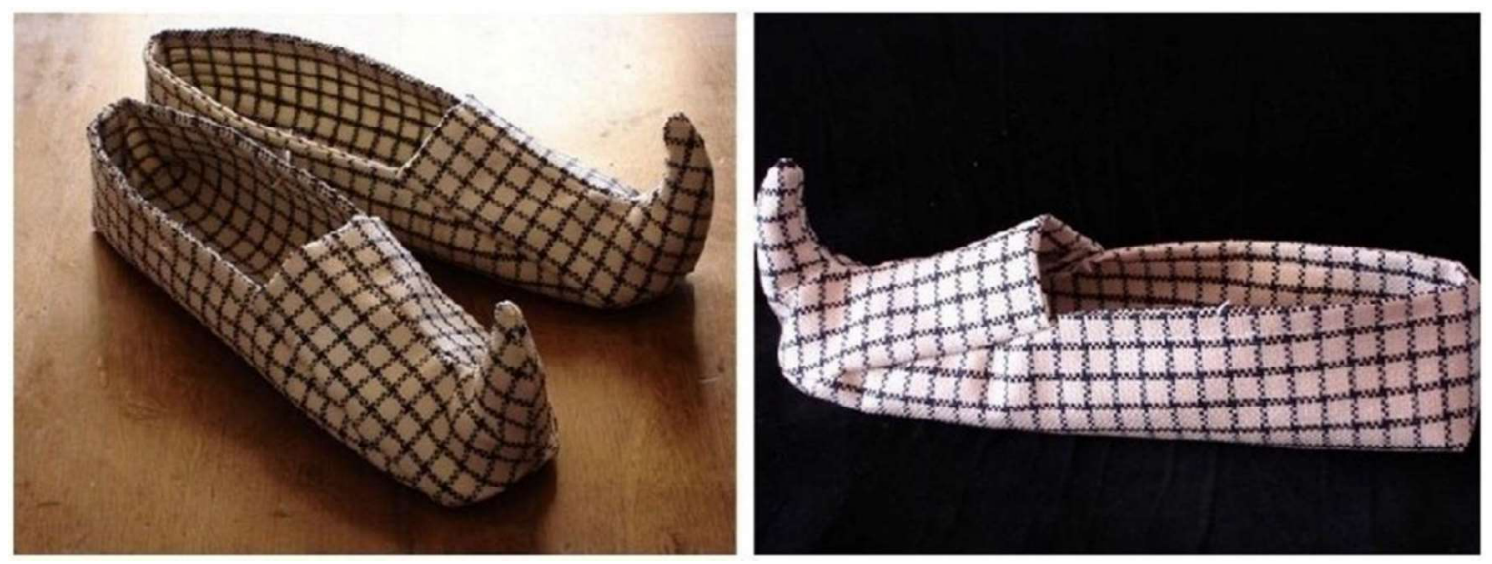

Figura 5

Carlos Pasquetti, Energiczador Catarina, 2006.

Sua obra Energiczador Catarina (2006) é o conjunto de duas imagens fotográficas (um díptico) que apresentam o que parecem ser sapatos em estilo

${ }^{21}$ Arthur Schopenhauer, O mundo como vontade e representação, 2001, p. 9. 
oriental, na imagem da esquerda um par e na da direita um pé. Na primeira imagem, é possível identificar uma superfície de madeira, sobre a qual descansam os supostos calçados. Na segunda, o objeto se encontra flutuando sobre um fundo totalmente escuro. Nas duas fotografias têm-se a impressão de terem sido iluminadas por luz natural, vinda de uma janela. Ao observar detalhes de acabamento das peças, confeccionadas com um tecido xadrez de algodão natural riscado em preto, é possível perceber a ausência de alguns componentes essenciais a um calçado, como palmilha ou solado. Este último sendo o elemento que, no tipo de calçado aludido pela representação fotográfica, é o que tem na extensão curva de sua ponta o motivo decorativo que, em alguns exemplares produzidos no Oriente Médio, pode chegar a medir, do calcanhar à ponta, mais de $70 \mathrm{~cm} .{ }^{22}$

O título do trabalho reúne dois elementos poético-retóricos que têm conexão com momentos diferentes da produção do artista. O primeiro elemento, a expressão energiczador, Pasquetti tem utilizado há pelo menos 20 anos, para designar trabalhos que envolvem tecidos com diferentes cortes e acabamentos, mas que sempre carregam alguma dúvida sobre a inutilidade daquelas peças e muita energia proporcionada pela certeza do conforto daqueles itens que sempre vestem bem. O segundo elemento, o nome feminino, o artista tem empregado em alguns trabalhos muito significativos, como em Ninayrosa (2011), apresentado na $8^{\text {a }}$ Bienal do Mercosul, em Doralice Collection + 5!!!, título da exposição realizada em 2016 na Pinacoteca Ruben Berta, e no Energiczador Catarina. Mais do que evocar a presença do feminino em suas preocupações poéticas, esses títulos também funcionam como sugestões, ou pistas, para o observador no desafio de interpretação. Elas interagem com os trabalhos que acompanham, menos condicionando leituras do que agenciando novos desdobramentos possíveis, desde que agem retoricamente a partir de um nível poético. A ironia surge como decorrência da sugestão, proposta pelo artista e empreendida pelo observador, do

${ }^{22}$ Peabody Museum of Archaeology and Ethnology at Harvard University, Length of Fashion, 2015. 
relacionamento do nome com a coisa. Se a arte contemporânea rejeita a ideia de confinamento da coisa em si, o uso do que seria uma descrição verbal da coisa, ou uma tautologia, como um emulador do trabalho, recorre ao próprio efeito irônico de dizer uma coisa querendo dizer outra ao afirmar talvez o mesmo, talvez não. A expressão Energiczador Catarina, por exemplo, conduziu a minha leitura do trabalho a uma imagem, lembrança de um relato que ouvi, que relaciona a forma cônica e recurva da ponta do suposto calçado com energia e com Catarina.

Talvez seja interessante, para confrontar a ideia da imagem visual como um documento da realidade, observar uma imagem conduzida por uma descrição verbal: era 28 de março de 2004 na cidade brasileira litorânea de Torres. Tarde. Houvera o aviso do serviço de meteorologia de que uma tempestade tropical se aproximava da costa sul do estado de Santa Catarina e fatalmente atingiria toda a região. A chuva que caía parecia ser de um tipo diferente do comum para aquela época, mas os habitantes locais aparentemente não estavam dando todo o crédito que a previsão do tempo mostraria, mais tarde, merecer. Uma insuperável tormenta se abateu sobre aquele balneário, que parecia não estar preparado para a violência com a qual esse surpreendente fenômeno da natureza expressa sua existência. Era o furacão Catarina. O vento parecia ter vida própria, e estava transtornado, arrancando árvores pela raiz e as jogando sobre carros e postes e vidraças de prédios que se espatifavam como se fossem feitos de areia. A areia da praia foi completamente retirada de onde estava e, junto com uma quantidade inacreditável de água salgada, foi utilizada para lavar e encharcar cada centímetro de cada canto da mais elevada habitação, agora já sem janelas e portas. Não há registro de outro furacão no Atlântico Sul. ${ }^{23}$

A imagem é dada por uma descrição visual, verbal, verbo-visual, ou pela participação e combinação de quaisquer dos sentidos humanos associados à interpretação que se faz daquilo que é percebido. No caso da descrição verbal, especialmente, há uma indução ou uma condução da interpretação daquilo que é

${ }^{23}$ Gary Padgett, Monthly Global Tropical Cyclone Summary March 2004, 2004. 
relatado, mas a imagem também é condicionada por sua construção, e condicionadora de suas possíveis leituras. O exercício do discernimento sobre o que há de verdade em uma imagem passa primariamente por aquele "patrimônio cognoscitivo" legado por milênios de experiência de caça, "farejar, registrar, interpretar e classificar pistas infinitesimais." ${ }^{24}$ A astúcia na perseguição leva a uma aproximação com a presa, mas, eventualmente, por força de determinadas circunstâncias, a presa escapa. A verdade na descrição, assim como a inverdade, depende da determinação daquele que dispõe (d)os fatos, segundo a sua visão. A fotografia carrega um crédito indicial que tende a limitar a sua leitura. "Enquanto índice, a fotografia é por natureza um testemunho irrefutável da existência de certas realidades." 25 Tudo aquilo que é evidente na fotografia é um empecilho à investigação de possibilidades não contempladas ali. Georges Didi-Huberman, em seu livro Ante el tiempo, quando emprega o conceito de imagem dialética, comenta a afirmação de Carl Einstein de que toda forma precisa é um assassinato de outras versões: "[...] esta admirable proposición enuncia el caráter dialéctico de todo trabajo formal, es decir, de toda descomposición de la forma por sí misma."26

A ansiedade pela definição é um inimigo da acuidade da percepção, e da arte. As fotografias de Pasquetti descrevem uma imagem, e oferecem indícios da irrealidade dessa imagem. A percepção dessa irrealidade conduz à descoberta da verdade da arte, a proposição da possibilidade, e à negação da contingência na apreensão da realidade, à destruição do pré-conceito, à fruição. Os elementos que compõem a obra, o objeto construído de forma a parecer um calçado, estranho à realidade local, a imagem dessa simulação retratada com a luz local e a atribuição de uma identificação verbal, o título, interagem. Aquilo que é estranho ou insólito, como o sapato de bico arrebitado dos hititas da Anatólia de cerca de 1500 a.C., ou um furacão no Atlântico Sul, carrega uma energia capaz de remover o

\footnotetext{
${ }^{24}$ Carlo Ginzburg, Raízes de um paradigma indiciário, 1989, p. 151.

${ }^{25}$ Philippe Dubois, O ato fotográfico e outros ensaios, 2012, p. 74.

${ }^{26}$ Georges Didi-Huberman, Ante el tiempo, 2008, p. 276.
} 
observador de sua posição segura, sabida. É destruição, mas, ironicamente, é possibilidade de criação.

A função da caça é a nutrição, porém a riqueza da cultura da caça não se resume à violência necessária à subsistência. As atividades humanas mais simples são revestidas de uma miríade de significados sutis que se somam na construção da experiência de vida. Se um furacão é uma força destrutiva a ser temida, ele também carrega, em sua imagem, a energia estética do sublime. A destruição da realidade da imagem promovida pelo Energiczador Catarina ao mesmo tempo tem a potência de criação de novas realidades, imaginadas. As imagens que nos dá a realidade, cridas como reais, continuam sendo a justaposição das projeções dos indícios encontrados pelo caminho.

O reconhecível oferece um suporte para a investigação visual a respeito da natureza do objeto. Se é uma fotografia o conteúdo da imagem, deve ser uma tomada da realidade, algo do mundo real retratado. $O$ inusitado da criação de um objeto, alvo da fotografia, aparentemente sem a funcionalidade que seria indispensável para um par de sapatos reais, reforça a sua potencialidade simbólica. E a sugestão dada pelo artista no título da obra encoraja o observador a perscrutar a miríade de possibilidades que giram à volta do ponto de convergência que a imagem origina. Tal como um turbilhão que se colocasse como a força capaz de transformar a realidade, na imagem de Pasquetti essa força poderia ser simbolicamente representada pelo alongado bico oriental do suposto calçado, a dialética da dupla irrealidade da imagem devasta a realidade do objeto, suplantado pela realidade da imagem. E a própria imagem só tem a validade de ser constantemente ocasião para um querer superar a imagem, sem que, contudo, isto aconteça. Querer superar a realidade é uma ação de destruição empreendida por cada indivíduo na busca de encerrar em sua subjetividade a satisfação de haver superado a realidade. "Entretanto, este ponto de vista é precisamente a ironia."27

\footnotetext{
${ }^{27}$ Søren Kierkegaard, Op. Cit., p. 164.
} 


\section{Referências}

BARTHES, Roland. A Câmara Clara: nota sobre a fotografia. Tradução de Júlio Castañon Guimarães. Rio de Janeiro: Nova Fronteira, 1984.

CALVINO, Italo. Em memória de Roland Barthes. In CALVINO, Italo. Coleção de areia. Tradução Maurício Santana Dias. São Paulo: Companhia das Letras, 2010. p. 81-86.

CALVINO, Italo. The adventure of a photographer. In CALVINO, Italo. Difficult loves. London: Vintage Books, 2010. p. 40-53. Disponível em:

https://is.gd/oaxjRe. Acesso em: 20 abr. 2019.

DIDI-HUBERMAN, Georges. Ante el tiempo: historia del arte y anacronismo de las imágenes. Tradução de Antonio Oviedo. Buenos Aires: Adriana Hidalgo, 2008.

DIDI-HUBERMAN, Georges. O rosto e a terra: Onde começa o retrato, onde se ausenta o rosto. Porto Arte, Porto Alegre, v. 9, n. 16, p. 61-82, maio 1998.

Disponível em:

http://seer.ufrgs.br/index.php/PortoArte/article/view/27751/16351. Acesso em: 20 abr. 2019.

DUBOIS, Philippe. O ato fotográfico e outros ensaios. Campinas: Editora Papirus, 2012.

FERREIRA, C. B. J. A ironia no trabalho de Carlos Pasquetti: A autoimagem performatizada como aporia. 2017. 250f. Dissertação (Mestrado em História, Teoria e Crítica de Arte) - Programa de Pós-graduação em Artes Visuais do Instituto de Artes, Universidade Federal do Rio Grande do Sul, Porto Alegre, 2017. Disponível em: <https://lume.ufrgs.br/handle/10183/169579>. Acesso em: 20 abr. 2019. 
FRANCASTEL, Galienne; FRANCASTEL, Pierre. El retrato. Traducción Esther Alperín. Madrid: Ediciones Cátedra, 1978. (Cuadernos Arte Cátedra).

FREUND, Gisèle. Photographie et société. Paris: Éditions Du Seuil, 2000.

GINZBURG, Carlo. Raízes de um paradigma indiciário. In: GINZBURG, Carlo. Mitos, emblemas, sinais: Morfologia e história. Tradução Federico Carotti. São Paulo: Companhia das Letras, 1989. p. 143-179.

HEGEL, Georg W. F. Lectures on the history of philosophy. London: Kegan Paul, Trench, Trübner \& Co., Ltd., 1892. v. 1.

HILL, Richard W.; WYSE, Gordon A.; ANDERSON, Margaret. Fisiologia Animal. 2. ed. Porto Alegre: Artmed, 2012. Disponível em: https://is.gd/wa99ET. Acesso em: 20 abr. 2019.

HOBBES, James R. The picture collector's manual: adapted to the professional man and the amateur. London: T. \& W. Boone, 1849. Disponível em: https://archive.org/stream/picturecollecto00hobbgoog\#page/n0/mode/2up. Acesso em: 20 abr. 2019.

JANKÉLÉVITCH, Vladimir. L'ironie. Manchecourt: Flammarion, 2011.

KIERKEGAARD, Søren. O conceito de ironia: constantemente referido a Sócrates. Tradução de Álvaro Luiz Montenegro Valls. Petrópolis: Vozes, 2013. (Vozes de bolso).

PADGETT, Gary. Monthly Global Tropical Cyclone Summary March 2004. 2004. Disponível em: http://australiasevereweather.com/cyclones/2004/summ0403.htm. Acesso em: 20 abr. 2019.

PASQUETTI, Carlos. Entrevista concedida ao autor. Porto Alegre, set. 2013. 5 arquivos .mp3 (1h35m49s). 
PASQUETTI, Carlos. Entrevista concedida ao autor. Porto Alegre, mar. 2015. 2 arquivos .mp3 (52min.).

PEABODY MUSEUM OF ARCHAEOLOGY AND ETHNOLOGY AT HARVARD UNIVERSITY. Length of Fashion. 2015. Disponível em:

https://www.peabody.harvard.edu/node/518. Acesso em: 20 abr. 2019.

PERELMAN, Chaïm; OLBRECHTS-TYTECA, Lucie. Tratado da argumentação: A nova retórica. Tradução de Maria Ermantina Galvão G. Pereira. São Paulo: Martins Fontes, 1996.

PLATO. Socrates Of Athens: Euthyphro, Socrates' Defense, Crito and the Death Scene from Phaedo. Translated by Cathal Woods \& Ryan Pack. Norfolk, VA: Cathal Woods, 2007. Disponível em:

http://rocket.csusb.edu/ tmoody/Apology,\%20plain,\%20new\%20trans.pdf. Acesso em: 20 abr. 2019.

PLINY (the elder). The Natural History of Pliny. London: H. G. Bohn, 1857. v. 6.

SCHOPENHAUER, Arthur. O mundo como vontade e representação. Tradução de M. F. Sá Correia. Rio de Janeiro: Contraponto, 2001.

Referência para citação deste artigo FERREIRA, Cláudio. A ironia no trabalho fotográfico de Carlos Pasquetti. Revista PHILIA |Filosofia, Literatura \& Arte, Porto Alegre, volume 1, número 2, p. 167 - 191, outubro de 2019. 